\title{
Impact of glycemic state on hospital outcome in patients with acute coronary syndrome in Sohag University hospitals
}

\author{
Eman Elsliney. Adel El Sayed, Hamdy Saad, Ahmed Hussein. \\ Internal Medicine Department, Faculty of Medicine, Sohag \\ University.
}

\begin{abstract}
Background
\end{abstract}

Hyperglycemia is common and related to more morbidity and death rates in hospitalized patients with acute coronary syndromes (ACS). We planned to research the relationship between the glycemic state and the hospital outcomes in ACS patients.

\section{Methods}

It was a prospective cohort study in included 150 patients admitted to the coronary care unit (CCU) with ACS at Sohag University hospital and were followed up for one month. We classified the patients into three gatherings regarding their glycemic state, group A (euglycemic), group B (hyperglycemia and not diabetic), and group C (hyperglycemia and known to be diabetic).

\section{Results}

We found no significant difference in the individual hospital outcomes, including serious arrhythmia, acute pulmonary edema, cardiogenic shock, recurrent ischemia, heart failure, cerebrovascular stroke (CVS), or all-cause deaths in the three groups. There was a significantly higher total outcome in hyperglycemic patients (group B+ C) compared to euglycemic patients (group A) after multivariate regression analysis and confounders adjustment (Adjusted OR was 1.79; 95\% CI 1.31-3.12; p-value $0.01)$.

Conclusion:In both diabetic and non-diabetic patients presented with ACS, the admission hyperglycemia has a harmful impact on the hospital outcomes. So, strict monitoring of the blood glucose levels at admission for all ACS patients is required, and tight management of hyperglycemia is mandatory.

Keywords: ACS, DM, Hyperglycemia, hospital outcomes.

\section{Introduction}

There are a few immovably settled hazard factors for cardiovascular disease, for example, family history, increment age, smoking, diabetes mellitus (DM), high blood cholesterol, hypertension, overweight and physical latency. DM is exceptionally connected with a high hazard for coronary artery disease (CAD) [1]. Subjects with DM have a considerably expanded danger of death after ACS than non-diabetic age-matched controls [2].

Hyperglycemia in patients admitted with ACS is common and related to more danger of death in diabetic and non-diabetic patients [3]. The high prevalence of undiscovered abnormal blood glucose metabolism in ACS patients perfect with prediabetes, similarly to frank DM, may to a limited extent clarify the relationship 
between the admission glucose levels and death. Mainly those who are not known to have DM at the hour of ACS [4]. Even though hyperglycemia might be inconvenient for the ischemic myocardium, in numerous patients, it might instead address a marker of the metabolic abnormalities gathered in the insulin resistance syndrome, which is related to cardiovascular diseases [5]. Admission hyperglycemia is a trustworthy hazard factor for death in ACS patients and might be significantly more grounded than a DM history. Evidence has demonstrated that ongoing glucose deregulation, as surveyed by glycated hemoglobin (HbA1c) levels, may be of prognostic value concerning the future cardiovascular illness. Besides, acute glycometabolic disturbances may negatively affect results as elevated glucose levels on admission are related to more adverse events, regardless of diabetic status [6].

\section{Methods}

It was a prospective cohort study in included 150 ACS patients (unstable angina (UA), non-ST elevation myocardial infarction (NSTEMI), and ST-elevation myocardial infarction (STEMI)) admitted to the CCU at Sohag University Hospital. We classified the patients into three equal groups; Group A patients with euglycemia, Group B patients with hyperglycemia and not diabetic, and Group C patients with hyperglycemia and known to be diabetic.

All the picked patients write an informed consent to participate in the research. The ethics committee of the Sohag Faculty of Medicine approved the study protocol.

All Patients above 18 years old admitted to CCU with ACS were considered to share in the study.

We excluded pregnant lady, and patients with end-stage disease that might affect the prognosis of the patients as advanced malignancy, chronic renal failure, and advanced liver disease

Data collection:

- Baseline demographic and clinical characteristics were collected, including age, gender, history of DM, history of hypertension, history of dyslipidemia, smoking, body mass index (BMI), and clinical presentation (UA, STEMI, or NSTEMI)

- Laboratory investigations included random blood sugar on admission (RBS), HbAIc level, lipogram, and cardiac enzymes (Troponin I, and cardiac-specific creatine phosphokinase (CKMB)

- Resting 12 lead ECG to identify signs of myocardial ischemia and cardiac rhythm.

- Echocardiography estimates systolic and diastolic cardiac chambers dimensions, resting segmental wall motion abnormalities, cardiac valves evaluation, and the left ventricle ejection fraction (LVEF) applying biplane Simpson's rule.

Follow up was done during the hospital stay and for one month either by telephone communication or clinic visit to detect any of the individual hospital outcomes included serious arrhythmia, acute pulmonary edema, cardiogenic shock, recurrent ischemia, heart failure, CVS or allcause deaths, and the total outcome.

\section{Definitions}

1. We considered the patient diabetic if (1) other than during pregnancy he had a physician previously told him that he has diabetes, or (2) taking anti-diabetic treatment [7].

2. Systemic hypertension was defined as a systolic blood pressure $\geq 140$ and diastolic blood pressure $\geq 90$ 
$\mathrm{mmHg} \quad$ and/or using antihypertensive therapy [8].

3. We calculated BMI from weight (kilograms) \& height (meters) by the equation $(\mathrm{BMI}=$ weight / (height $)^{2}$ ). Weight was measured a little closest to $0.5 \mathrm{Kg}$, and the height was measured (bared feet) to the closest $0.5 \mathrm{~cm}$. BMI is viewed as raised at $\geq 25 \mathrm{~kg} / \mathrm{m}^{2}$ [9].

\section{Statistical analysis}

We analyzed the data using SPSS software version 19. The quantitative data were analyzed by the analysis of variance (ANOVA), comparing the three studied groups' means. The qualitative data were analyzed utilizing the Chi-square test. When the expected cell count is $<5$, we used Fisher's exact correction. Univariate analysis and Multivariate regression analyses between the sum of outcomes and the glycemic state after adjusted for the confounders were performed. We had three comparison groups, so the Bonferroni correction was applied, and the $\mathrm{p}$-value was viewed as significant $\leq$ 0.0167 .

\section{Results}

Out of 150 patients included in our study, the three groups' baseline characteristics showed no significant difference in mean age, sex, smoking, and clinical presentation. In contrast, hypertension, dyslipidemia, and mean BMI were statistically significantly higher in hyperglycemic patients (group B and group C) than euglycemic patients (group A). (Table 1-4)

Univariate analysis of the hospital outcomes showed no significant difference in the individual outcomes (serious arrhythmia, acute pulmonary edema, cardiogenic shock, recurrent ischemia, heart failure, CVS, or allcause deaths) between the three studied groups, but the total outcome was significantly higher in hyperglycemic patients (group B, and group C) compared to euglycemic patients (group A) and there was statistically insignificant difference between group B, and group C. (Table 5)

Multivariate regression analysis for the total outcome after adjustment for confounders showed that it was significantly higher in hyperglycemic patients (group $\mathrm{B}+\mathrm{C}$ ) compared to euglycemic patients (group A) (Adjusted OR was 1.79; 95\% CI 1.313.12; p-value 0.01).. (Table 6)

\begin{tabular}{|c|c|c|c|c|}
\hline Variable & $\begin{array}{c}\text { Group A } \\
\text { (Euglcemic) }\end{array}$ & $\begin{array}{c}\text { Group B } \\
\text { (Hyperglycemia, } \\
\text { not diabetics) }\end{array}$ & $\begin{array}{c}\text { Group C } \\
\text { (Hyperglycemia, } \\
\text { diabetics) }\end{array}$ & P-value \\
\hline $\begin{array}{c}\text { Age (years) } \\
\text { Mean } \pm \text { SD } \\
\text { Median(range) }\end{array}$ & $\begin{array}{c}61.66 \pm 8.89 \\
60(42-83)\end{array}$ & $\begin{array}{c}60.74 \pm 9.67 \\
60(39-90)\end{array}$ & $\begin{array}{c}60.38 \pm 6.32 \\
60(43-70)\end{array}$ & 0.74 \\
\hline $\begin{array}{c}\text { Sex } \\
\text { Females } \\
\text { Males }\end{array}$ & $24(48.00 \%)$ & $17(34.00 \%)$ & $23(46.00 \%)$ & 0.31 \\
\hline $\begin{array}{c}\text { Smoking } \\
\text { Yes }\end{array}$ & $26(52.00 \%)$ & $33(66.00 \%)$ & $27(54.00 \%)$ & 0.44 \\
\hline $\begin{array}{c}\text { Hypertension } \\
\text { Yes }\end{array}$ & $11(22.00 \%)$ & $18(36.00 \%)$ & $24(48.00 \%)$ & $<0.001$ \\
\hline $\begin{array}{c}\text { Dyslipidemia } \\
\text { Yes }\end{array}$ & $9(18.00 \%)$ & $19(38.00 \%)$ & $43(66.00 \%)$ & $<0.001$ \\
\hline $\begin{array}{c}\left.\text { BMI (kg/m }{ }^{2}\right) \\
\text { Mean } \pm \text { SD }\end{array}$ & $25.27 \pm(2.41)$ & $26.11 \pm(2.31)$ & $27.66 \pm(4.55)$ & $<0.001$ \\
\hline \multicolumn{2}{|l}{} & $30(60.00 \%)$ & & \\
\hline
\end{tabular}

Table (1) Baseline characteristics and risk factors of the studied population 


\begin{tabular}{|l|l|l|l|l|}
\hline $\begin{array}{l}\text { Clinical } \\
\text { presentation }\end{array}$ & Group A & Group B & Group C & $\begin{array}{l}\text { P- } \\
\text { value }\end{array}$ \\
\hline UA & $19(38.00 \%)$ & $18(36.00 \%)$ & $16(32.00 \%)$ & 0.26 \\
NSTEMI & $16(32.00 \%)$ & $15(30.00 \%)$ & $17(34.00 \%)$ & 0.19 \\
STEMI & $15(30.00 \%)$ & $17(34.00 \%)$ & $17(34.00 \%)$ & 0.57 \\
\hline
\end{tabular}

Table (2)

Clinical presentation of the studied population

\begin{tabular}{|c|c|c|c|c|}
\hline Variable & Group A & Group B & Group C & $\begin{array}{l}P \text { - } \\
\text { value }\end{array}$ \\
\hline \multicolumn{5}{|l|}{ Cholesterol level } \\
\hline Mean \pm SD & $163.6 \pm 62.72$ & $183.06 \pm 35.30$ & $209.8 \pm 40.14$ & $<0.00$ \\
\hline Median (range) & $139.5(68-386)$ & $177.5(110-250)$ & $207.5(130-303)$ & 1 \\
\hline \multicolumn{5}{|c|}{$\mathrm{p} 1<0.001, \mathrm{p} 2<0.001, \mathrm{p} 3<0.001$} \\
\hline \multicolumn{5}{|l|}{ Triglyceride level } \\
\hline Mean \pm SD & $128.66 \pm 52.76$ & $162.62 \pm 45.54$ & $187.84 \pm 49.92$ & \multirow[t]{2}{*}{$<0.001$} \\
\hline Median (range) & $127(40-253)$ & $158.5(80-259)$ & $200(59-260)$ & \\
\hline \multicolumn{5}{|c|}{$\mathrm{p} 1<0.001, \mathrm{p} 2<0.001, \mathrm{p} 3<0.001$} \\
\hline LDL level & & & & \multirow{3}{*}{$<0.001$} \\
\hline Mean \pm SD & $77.56 \pm 16.12$ & $91.8 \pm 19.23$ & $106.03 \pm 19.33$ & \\
\hline Median (range) & $76.5(50-119)$ & $90(50-132)$ & $110(67-150)$ & \\
\hline \multicolumn{5}{|c|}{$\mathrm{p} 1<0.001, \mathrm{p} 2<0.001, \mathrm{p} 3<0.001$} \\
\hline HDL level & & & & \multirow{3}{*}{0.023} \\
\hline Mean \pm SD & $39.24 \pm 9.88$ & $39.8 \pm 11.5$ & $34.6 \pm 8.11$ & \\
\hline Median (range) & $37.5(27-60)$ & $37.5(25-62)$ & $32(25-56)$ & \\
\hline \multicolumn{5}{|c|}{$\mathrm{P} 1=0.97, \mathrm{p} 2=0.012, \mathrm{p} 3=0.025$} \\
\hline
\end{tabular}

Table (3): Lipid profiles of the studied population

P1 compared group A with group B, P2 compared group A with group C, P3 compared group B with group C

\begin{tabular}{|l|l|l|l|l|}
\hline Variable & Group A & Group B & Group C & $\begin{array}{l}\text { P- } \\
\text { value }\end{array}$ \\
\hline $\begin{array}{l}\text { Random blood sugar } \\
\text { Mean } \pm \text { SD } \\
\text { Median (range) }\end{array}$ & $\begin{array}{l}118.56 \pm 10.73 \\
120(99-137)\end{array}$ & $\begin{array}{l}258.32 \pm 73.46 \\
249.5(155-500)\end{array}$ & $\begin{array}{l}257.68 \pm 77.21 \\
230(180-500)\end{array}$ & $<0.001$ \\
\hline \multicolumn{5}{|c|}{$\mathrm{p} 1<0.001, \mathrm{p} 2<0.001, \mathrm{p} 3=0.53$} \\
\hline HbA1c & $\begin{array}{l}5.73 \pm 0.43 \\
\text { Mean } \pm \text { SD }\end{array}$ & $\begin{array}{l}5.77 \pm 0.57 \\
6(4.5-6.5)\end{array}$ & $\begin{array}{l}9.11 \pm 1.69 \\
8.65(7-14)\end{array}$ & $<0.001$ \\
\hline Median (range) & $5.9(4.8-6.4)$ & $\mathrm{p} 1=0.42, \mathrm{p} 2<0.001, \mathrm{p} 3<0.001$ \\
\hline
\end{tabular}

Table (4):

Random

blood sugar and HbA1c level of the studied population

P1 compared group A with group B, P2 compared group A with group C, P3 compared group B with group C 


\begin{tabular}{|c|c|c|c|c|c|}
\hline Variable & Group A & Group B & Group C & P-value & \multirow{2}{*}{$\begin{array}{l}\text { Table (5): } \\
\text { Univariate } \\
\text { analysis for }\end{array}$} \\
\hline Total outcome & $5(10.00 \%)$ & $17(34.00 \%)$ & $26(52.00 \%)$ & 0.002 & \\
\hline \multicolumn{5}{|c|}{$\mathrm{p} 1<0.0001, \mathrm{p} 2<0.0001, \mathrm{p} 3=0.07$} & \\
\hline $\begin{array}{l}\text { Individual } \\
\text { outcomes }\end{array}$ & & & & & of the \\
\hline Serious arrhythmia & $1(20.00 \%)$ & $2(16.66 \%)$ & $3(15.78 \%)$ & 0.26 & studied \\
\hline Pulmonary edema & $1(20.00 \%)$ & $2(16.66 \%)$ & $78 \%)$ & 0.26 & population \\
\hline Cardiogenic shock & 0 & $1(8.33 \%)$ & $2(10.52 \%)$ & 0.94 & \\
\hline Recurrent ischemia & $1(20.00 \%)$ & $3(25.00 \%)$ & $5(26.31 \%)$ & 0.16 & \\
\hline Heart failure & $1(20.00 \%)$ & $3(25.00 \%)$ & $4(21.00 \%)$ & 0.11 & \\
\hline CVS stroke & $1(20.00 \%)$ & $1(8.33 \%)$ & $2(10.52 \%)$ & 0.98 & \\
\hline All-cause death & 0 & $5(10.00 \%)$ & $7(14.00 \%)$ & 0.30 & \\
\hline
\end{tabular}

\begin{tabular}{|l|lcl|lcc|}
\hline Variable & \multicolumn{4}{|l|}{$\begin{array}{l}\text { Unadjusted OR (95\% CI) for } \\
\text { hyperglycemic patients (group B+ C) } \\
\text { versus euglycemic (group A) (reference) }\end{array}$} & $\begin{array}{l}\text { Adjusted OR (95\% CI) } \\
\text { patients } \\
\text { (group A) (group B+ C) }\end{array}$ & $\begin{array}{l}\text { for hyperglycemic } \\
\text { versus euglycemic }\end{array}$ \\
\hline Total & OR & $95 \%$ CI & p value & OR & $95 \%$ CI & p value \\
outcome & 2.25 & $1.89-3.54$ & 0.005 & 1.79 & $1.31-3.12$ & 0.01 \\
\hline
\end{tabular}

Table 6: Multivariate regression analyses for the total outcome and the glycemic state.

Abbreviations: CI, confidence interval: OR, odds ratio

\section{Discussion}

Our study showed that admission hyperglycemia did not significantly affect the individual hospital outcomes but largely affected the total outcome for diabetic and non-diabetic patients presented by ACS. We may explain the insignificant difference in the individual outcomes by the study participants' small sample size. Our results were in concordance with Capes et al., who reported that the non-diabetic patients admitted with acute myocardial infarction (AMI) and admission glucose level $\geq 110 \mathrm{mg} / \mathrm{dl}$ had an in-hospital death rate of 3.9 in comparison with the non-diabetic AMI patients who had admission euglycemia. Also, diabetic patients with AMI and admission glucose level $\geq 180 \mathrm{mg} / \mathrm{dl}$ showed a $70 \%$ more risk of in-hospital death than diabetic patients with admission normoglycemia [3]. Foo et al. conducted a study among 2127 ACS patients and showed a nearlinear association between the higher admission serum glucose levels and the higher rates of left-sided heart failure and cardiac mortality [6]. Also, Meier et al. addressed a higher death rate and bigger infarct size among hyperglycemic patients (diabetics and non-diabetics) presented with AMI [9]. Wahab et al. and Stranders et al. have also suggested that hyperglycemia at admission was associated with an increased risk in AMI patients not previously known to have DM. These findings were discordant with our results. They found a higher incidence of poor outcomes related to admission hyperglycemia in patients without DM history. In our study, the higher incidence of poor outcomes was related to admission hyperglycemia in diabetic and non-diabetic patients. However, they agreed with our results in that admission hyperglycemia had a great impact on outcomes in patients presented by ACS even more than the previous history of DM [10,11]. 
Many other previous studies confirmed our results in that non-diabetic and diabetic patients with admission hyperglycemia had a harmful impact on ACS outcomes [4, 12, 13, 14, 16].

In our study, the distribution of age, gender, and smoking among the three groups of participants showed no statistically significant difference, which means that age, gender, and smoking had no impact on ACS outcomes.

Turner et al., who studied the risk factors for CAD in patients who had non-insulin dependent DM, agreed with our results in that age and sex had no impact on the outcome in patients presented with ACS [13]. Also, Surekha et al. studied the risk factors for CAD in DM agreed with our results in that age and sex had no impact on the outcome in patients presented with ACS [14]. Our findings are also similar to the findings reported by Damaris et al., who studied admission glycemia and its outcomes in ACS patients in that age and sex had no impact on the patient's outcome who presented with ACS [15].

As regards smoking, we found that there was no significant difference among the three groups. Turner et al. and Surekha et al. also reported no significant difference in the prevalence of Cigarette smoking between the studied subgroups, which means that Cigarette smoking had no impact on the hospital outcomes in ACS patients $[13,14]$. On the contrary, Damaris et al. 2007 and Norhammar et al. 1999 addressed a significant difference between the study subgroups as regards the prevalence of Cigarette smoking, which means that Cigarette smoking had a significant effect on the outcome in patients presented with ACS, this finding was discordant with our results most probably due to our small patient's sample size $[15,16]$.

The prevalence of hypertension, dyslipidemia, and BMI among the studied patients was significantly higher in patients with hyperglycemia than those with euglycemia. Damaris et al. reported a significant difference between their study subgroups regarding the prevalence of hypertension and showed that hypertension significantly impacted the outcome in diabetic patients presented by ACS. These findings agree with our results that hypertension impacted the outcome in diabetic patients presented with ACS [15].

On the contrary, Turner et al. and Surekha et al. reported that the prevalence of hypertension between the studied subgroups was not significantly different, which means that hypertension had no impact on the outcome in DM patients presented by ACS. [13, 14].

As regards ST-segment deviation (ST elevation or depression) and levels of cardiac enzymes that suggested the type of ACS (UA, NSTEMI, or STEMI) among patients in the study, we found that there was no significant difference between the three studied groups as regards ST-segment deviation and levels of cardiac enzymes. Norhammar et al. 2004 reported a non-significant difference between their study subgroups regarding ST-segment deviation, which means that ST-segment deviation had a non-significant impact on patients' outcomes presented by ACS [4]. Turner et al. reported a non-significant difference between their study subgroups regarding the number of patients with positive Troponin. This means that positive Troponin had a non-significant impact on the outcomes in diabetic patients presented by ACS. these findings of Turner et al. were in concordance to our results in that positive Troponin had no impact on the outcomes in patients presented by acute coronary syndrome [13].

\section{Conclusions}

Hypertension, dyslipidemia, and increased BMI may adversely affect patients' outcomes presented by ACS. Also, in diabetic and non-diabetic 
patients, the admission hyperglycemia negatively impacts the hospital outcomes in ACS patients. So, strict monitoring of serum glucose levels at admission for all patients presented with ACS, diabetic and non-diabetic patients is required, and tight management of hyperglycemia is mandatory

\section{References}

1. Kannel WB, McGee DL: Diabetes and cardiovascular disease: the Framingham study. JAMA, 2004. 241: 2035 - 2038.

2. Malmberg $\mathrm{K}$, Rydén $\mathrm{L}$, Wedel $\mathrm{H}$, et al: DIGAMI 2 Investigators .Intense metabolic control by means of insulin in patients with diabetes mellitus and acute myocardial infarction (DIGAMI 2): effects on mortality and morbidity. Eur Heart J. 2004; 26:650661.

3. Capes SE, Hunt D, Malmberg K, et al: Stress hyperglycemia and increased risk for death after myocardial infarction in patients with and without diabetes: a systemic overview. Lancet, 2013, 355:773-778.

4. Norhammar A, Tenerz A, Nilsson G, et al: Glucose metabolism in patients with acute myocardial infarction and no previous diagnosis of diabetes mellitus: A prospective study. Lancet 2004; 359:2140.

5. Heine, R. J., \& Dekker, J. M.: Beyond postprandial hyperglycaemia: metabolic factors associated with cardiovascular disease. Diabetologia, 2011; 45 (4), 461-475.

6. Foo K, Cooper J, Deaner A, et al: A single serum glucose measurements predicts adverse outcomes across the whole range of acute coronary syndromes. Heart 2003; 89: $512-16$.

7. Standards of Medical Care in Diabetes. Diabetes Care 2015; 38 (Suppl 1): S3

8. Efrain Reisin, Raymond C. Harris, Mahboob Rahman. Commentary on the 2014 BP Guidelines from the Panel Appointed to the Eighth Joint National Committee (JNC 8). J Am Soc Nephrol. 2014 Nov; 25(11): 24192424.

9. Kenneth F. Arthur Schatzkin, Tamara B. Harris, et al. Overweight, Obesity, and
Mortality in a Large Prospective Cohort of Persons 50 to 71 Years Old. N Engl J Med 2006; 355:763-778

10. Meier JJ, Deifuss S, Klamann A, et al: Plasma glucose at hospital admission and previous metabolic controldetermine myocardial infarct size and survival in patients with andwithout type 2 diabetes: the Langendreer Myocardial Infarction andBlood Glucose in Diabetic Patients Assessment (LAMBDA). Diabetes Care. 2005; 28:2551-2553.

11. Wahab NN, Cowden EA, Pearce NJ, et al: ICONS Investigators. Is blood glucose an independent predictor of mortality in acute myocardial infarction in the thrombolytic era? J Am CollCardiol. 2002; 40:17481754.9.

12. Stranders, I., Diamant, M., Van Gelder, R., Spruijt, H., Twisk, J., Heine, R. Et al. Admission blood glucose level as risk indicator of death after myocardial infarction in patients with and without diabetes mellitus. Arch Intern Med 2004;164: 982-988

13. Mehta SR, Yusuf S, Diaz R, et al: CREATE-ECLA Trial Group. Effect of glucose-insulin-potassium infusion on mortality in patients with acute STsegment elevation myocardial infarction: theCREATE-ECLA randomized controlled trial. JAMA. 2005;293:437-446.

14. Turner R C, Millns H, Neil H A, et al: Risk factors for coronary artery disease in non-insulin dependent diabetes mellitus: United Kingdom prospective diabetes study (UKPDS: 23).BMJ 1998; 316; 823-828.

15. Surekha R, Madhavi1 G, Ramachandra $\mathrm{R}$, et al: risk factors for coronary heart disease in type ii diabetes mellitus. Indian Journal of Clinical Biochemistry, 2005, 20 (2) 75-80.

16. Damaris M, Dragana R, Edoardo $C$, et al: Admission glycaemia and outcome in 
patients with acute coronary syndrome. Diabetes and Vascular disease research, 2007, volume 4 issue 4. December.

17. Norhammar A, Tenerz A, Nilsson G,et al: Admission plasma glucose :independent risk factor for long-term prognosis after myocardial infarction even in nondiabetic patents. Diabetes Care, 1999,22: 1827- 1831 